\title{
Spouses Who Donate Seem to Be the Winners- A Questionnaire Study of Kidney Donors Long-Term
}

\author{
Annette Lennerling ${ }^{1,2}$, Abdul Rashid Qureshi ${ }^{3}$, Ingela Fehrman-Ekholm ${ }^{1,4}$ \\ ${ }^{1}$ Transplant Institute, Sahlgrenska University Hospital, Gothenburg, Sweden \\ ${ }^{2}$ Institute of Health and Care Sciences, University of Gothenburg, Gothenburg, Sweden \\ ${ }^{3}$ Baxter Novum, CLINTEC, Karolinska Institute, Stockholm, Sweden \\ ${ }^{4}$ Renal Department, Karolinska University Hospital, Stockholm, Sweden \\ Email: annette.lennerling@vgregion.se
}

Received August 8, 2012; revised September 10, 2012; accepted September 18, 2012

\begin{abstract}
Background: Living donor kidney transplantations have been performed at Sahlgrenska University Hospital in Gothenburg, Sweden since 1965. In this study we wanted to explore the living kidney donor's long-term experiences of the donation. Methods: Of 1110 consecutive living donors throughout 1965-2005, 823 were available for our questionnaire study. Results: Totally 692 replied to the questionnaire, $65 \%$ were females. The most common relation to the recipients was siblings (284), parents (262) and spouses (96). Time since donation was median 15 years (2 - 43). The initiative to donate came from the donors themselves in $69 \%$. The dominating motives for donation were a wish to help, worries about the recipient not receiving a transplant and the knowledge that one could live a normal life with one kidney. The majority of the donors, felt well informed about potential risks both short-term and long-term. Depression post donation was reported by few donors, $2.3 \%$ and persisting pain by $4.3 \%$. Comparisons between sibling donors and spouse donors show a significant difference $(\mathrm{p}<0.0001)$ in the statements; If I donate a kidney "My quality of life will be better" and "The quality of life for the family will be better" more so for spouses. Also spouses seemed to be better informed about risks both for themselves and the recipients $(\mathrm{p}<0.05)$. Conclusions: Our study shows that the donor population is in good psychosocial health. It is a positive progress that spouses can be living kidney donors- they seem to be the winners.
\end{abstract}

Keywords: Living Kidney Donors; Long-Term Follow-Up; Motives; Sibling; Spouse; Questionnaire

\section{Introduction}

Kidney transplantation with an organ from a live donor is the best treatment for the transplant recipient and living donation is increasing in many countries [1,2]. Both short and long term results are better. The recipients are followed closely but the donors check-up vary. Several studies have been published about the better life quality among the living donors compared to background population [3-5]. However, also better psychosocial support has been discussed since some donors have problems post donation [6,7].

In Sweden living kidney donors have been used for kidney transplantation since the start in 1964. Until $31^{\text {st }}$ of December 2011, 3704 living donor kidney transplanttations had been performed and 9238 kidney transplantations from deceased donors. The Transplant Institute at Sahlgrenska University Hospital in Gothenburg is the largest of four kidney transplant centres in Sweden with 1425 (31 $1^{\text {st }}$ of December 2011) living kidney donor transplantations since the start in 1965.

In Sweden, living donors are always the first choice for patients in need of a kidney transplant. The living donor pool has expanded from siblings and parents, to also include spouses, friends, as well as other more distant relatives and anonymous donors. Today live donors constitute about $45 \%$ of all kidney transplantations in Sweden. There is no national Swedish donor registry, but a Scandinavian register started in 2004. However, the donors from earlier days are not included. This is a prospective register and limited psychosocial issues are included in the report.

We were interested to know more about the living donors both the physical health status, and the psychosocial well-being. Further we wanted to find out more about their experiences of the donation process, motives for donating, relations with the recipient after donation and present health situation. This living donor study was initiated in 2007. The study was divided in two parts, one medical follow-up-mainly focusing on long-term renal function, and was published in 2011 [8]. In the second part of this study we wanted to explore the donor's experiences of the kidney donation in different aspects in the long term. We here present data and also put focus in 
comparing the experiences and thoughts from sibling donors and spouse donors. Today the spouse donor is as common as a sibling donor.

\section{Subjects and Methods}

The study design was cross sectional and the study was performed between the years 2007-2009. We aimed to approach all persons having had a donor nephrectomy performed at Sahlgrenska University Hospital from the start in May 1965 until the end of December in 2005, in total 1112 donors. Of the 1112 donors $13 \%$ were deceased, 6\% were not possible to identify due to incomplete social security number and $4 \%$ were living abroad, thus 823 persons, i.e. $77 \%$, were available for the study. Of the 8237/15/2012 donors, 692 participants responded to an author constructed questionnaire. The questionnaire consisted of 50 questions focusing on the living donors experiences of motives, information and health problems. There was no standardized health form added. The questionnaires were sent to the donor by post with one reminder to the non-responders. There was a possibility to reply on-line, which was used by $20 \%$ of the donors.

We used a software program for collecting the questionnaire data, the survey tool called Examinare ${ }^{\odot}$

(www. examinare.com). From this tool descriptive data were obtained. The forms that Examinare ${ }^{\circledR}$ creates are protected by Secure Socket Layer (SSL) and the information between server and browser is encrypted.

The study was approved by the ethical regional board in Gothenburg.

\section{Statistical Methods}

Normally-distributed variables were expressed as means \pm SD (unless noted otherwise), and non-normally distributed variables were expressed as medians $\left(10^{\text {th }}\right.$ and $90^{\text {th }}$ percentile). Statistical significance was set at the level of $\mathrm{p}<0.05$. Logistic regression analyses were used to study the relative associations of selected markers. All statistical analyses were performed using statistical software Stata version 12.1 (Stata Corp, College station, TX, USA). As $\mathrm{p}$ values are not adjusted for multiple testing, they have to be considered as descriptive.

\section{Results}

\subsection{Characteristics of the Donor Population}

The response rate for questionnaire was 84\%, 692 of the 823 available donors. Of those $65 \%(n=447)$ were females. The median age was 61 years (range 22 - 93). The median age at donation was 47 years (range 21 - 73). The similar trend was found in the non-responders. The relationship to the recipients was sibling $(\mathrm{n}=284)$, parent ( $\mathrm{n}$ $=262)$, spouse $(n=96)$, friend $(n=18)$, grown-up child $(n=7)$ and other relation $(n=26)$.

\subsection{Pre-Donation Statements by the Donors}

The occupational situation before donation is presented in Table 1. A high quantity of the donors 587 (84\%) were working at the time of donation, 21 were unemployed, 53 retired, 13 were students and 18 were house wives. None was disability pensioner. The initiative to donate came from the donors themselves in the majority of cases. Thus 474 (69\%) offered to donate, the recipients physician asked in 88 (13\%) cases, the recipients in 85 (12\%) cases. Other family member asked in 20 (3\%) cases. The most common motives for donation was the wish to help, worries about the recipient not receiving a transplant and the knowledge that one could live a normal life with one kidney. Generally, the becoming donors felt well informed about risks (76\%), short-term complications (69\%), and long-term complications (62\%). They also felt well informed about recipient risks (73\%) and that the given kidney might stop to function or even never function (75\%). The donors felt well-informed about the reimbursement system and sick leave regulations (67\%). We also asked if the information given was too much but only $3 \%$ of the donors stated that.

Table 1. Occupational status and statements by the 692 donors concerning issues before donation.

\begin{tabular}{lcc}
\hline Response on pre-donation issues & n & \% \\
\hline Working & 587 & 85 \\
Retired & 53 & 8 \\
Students & 13 & 2 \\
Unemployed & 21 & 3 \\
Other activities & 18 & 3 \\
\hline Took the initiative to donate & & \\
\hline Themselves & 474 & 68 \\
The doctor of the recipient & 88 & 13 \\
The recipient & 85 & 12 \\
Other family member & 20 & 3 \\
Other & 28 & 4 \\
\hline Most important motives to donate & & \\
\hline To help & & \\
\hline Worry without a transplantation & 518 & 75 \\
Knowledge: a normal life with one kidney & 497 & 72 \\
\hline Information & 240 & 35 \\
\hline Felt very well-informed about the risks & & \\
Short term complications & 528 & 76 \\
Tong term complications & 502 & 73 \\
The recipients risks & 517 & 75 \\
ment the given kidney might stop functioning & 69 & 3 \\
\hline
\end{tabular}


The experiences following donation are presented in Table 2. Time for recovery after donation was 1 - 2 months for $48 \%$ of the donors and $5 \%$ stated that they had never recovered. Sick leave time was 1 - 3 weeks for $22 \%, 4-7$ weeks for $37 \%$ and 8 - 12 weeks for $20 \%$. Longer sick leave than 12 weeks were reported by $4 \%$. The reimbursement system functioned completely for 325 donors (47\%), partly for 124 (18\%) but 98 donors (14\%) said they never received anything. However, only $7 \%$, that is 45 donors, considered they still had financial problems due to the donation. No one reported having lost their work due to the donation.

Health problems related to the donation were stated by $12 \%$ of the donors. Experienced kidney disease was stated in $2 \%$ and $27 \%$ had treated hypertension. Depression and diabetes were reported by a few cases, $2 \%$ for each and persisting pain problems by $4 \%$.

\subsection{Low Pregnancy Frequency among Living Donors}

The pregnancy frequency was low, 21 donors (5\% of the female donors) had given birth after donation. Most persons were middle-aged at the time of donation and not in childbearing ages. None reported the pregnancy as a problem.

\subsection{Spouses versus Siblings as Donors}

The three great donor groups are siblings, parents and spouses. From the start only siblings and parents were accepted as live kidney donors but since 1986 spouses were also permitted to donate.

Table 2. Statements by the 692 participants concerning post donation health issues.

\begin{tabular}{lcc}
\hline Recovery after donation & $\mathrm{n}$ & $\%$ \\
\hline 1 - 2 months & 331 & 48 \\
3 - 6 months & 210 & 30 \\
- 12 months & 62 & 9 \\
More than one year & 58 & 9 \\
Never recovered & 31 & 5 \\
\hline Time for sick leave & & \\
\hline 1 - 3 weeks & 154 & 22 \\
4 - 7 weeks & 254 & 37 \\
8 - 12 weeks & 140 & 20 \\
Longer time & 37 & 4 \\
Can't remember & 92 & 13 \\
\hline Experienced health after the donation & & \\
\hline Remaining health problems & 79 & 12 \\
Experienced kidney disease after donation & 11 & 2 \\
Experienced kidney stones & 25 & 4 \\
Developed diabetes & 12 & 2 \\
Had hypertension treatment today & 173 & 27 \\
Had continuous nerve pain & 28 & 5 \\
Muscle weakness in abdomen & 58 & 9 \\
Depression & 16 & 3 \\
Had been pregnant after donation & 21 & 5 \\
\hline
\end{tabular}

A comparison of the responses from the 96 spouses and the 284 siblings were made. In the following questions there were borderline or significant differences. There were no significant differences between the current age of spouses and siblings, Figure 1.

The following statements concern the motives for becoming a donor. The parentheses indicate the donor type being closest to the statement.

- Others wanted me to donate (sibling) $(\mathrm{p}=0.05)$

- Waiting-time for a deceased kidney was too long (spouse) $(p=0.05)$

- A moral duty to donate (sibling) $(\mathrm{p}=0.05)$

- My quality of life would be better (spouse) (p < 0.0001 )

- The quality of life all the family would be better (spouse) $(p<0.0001)$

The following statements are about the information prior to donation:

- Well-informed about risks for short term complications (spouse) $(\mathrm{p}<0.05)$

- Well-informed about risks for long-term complications (spouse) $(\mathrm{p}<0.05)$

- Well-informed about complications and risks in the recipients (spouse) $(\mathrm{p}<0.01)$

Statements and experiences after the donation:

- Feeling malaise first week post donation (spouse) ( $\mathrm{p}<$ 0.05)

- Better self-esteem (spouse) $(\mathrm{p}<0.05)$

- Changed to more frequent contact with the recipient (sibling) $(\mathrm{p}<0.01)$

- Would consider to donate again (spouse) $(\mathrm{p}<0.01)$

- Experienced pregnancy, children after the donation (sibling) $(\mathrm{p}<0.001)$

The following statements showed no differences between spouses and siblings regarding motives for donation: a

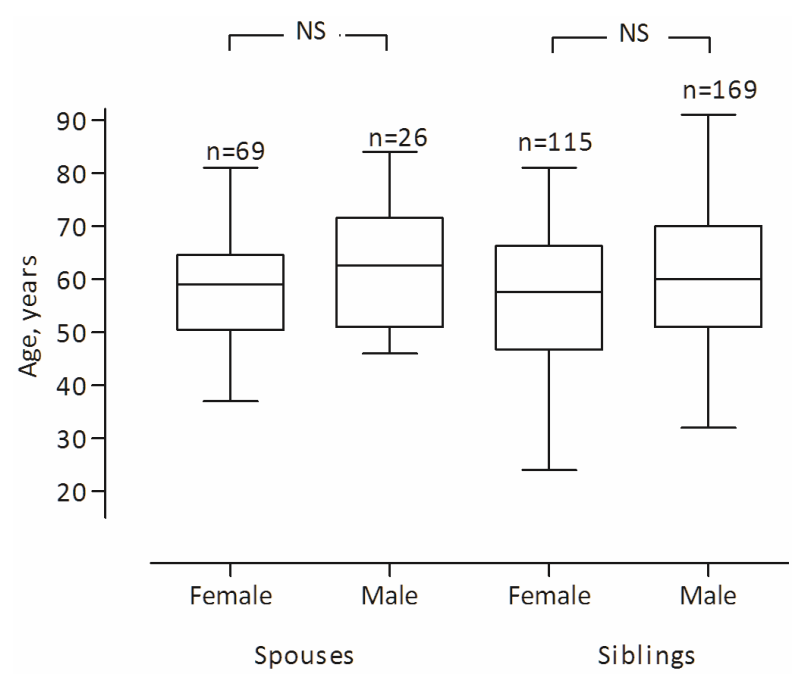

Figure 1. Box plot of the current age of spouses and siblings grouped in males and females. 
wish to help, religion, have a normal life with one kidney, the donations would make me a better person, worry for the recipient without a transplant, becoming a better person and seeing no other possibility than donating. Perception about getting information about the following subjects did not differ: re-imbursement system, surgical risks, follow-up routines, and the risk of graft failure for the recipient.

Time for recovery and sick-leave period did not differ between spouses and siblings. Further, there was no difference in percentage regretting the donation or having remaining health problems. Routines for check-ups did not differ either between the two groups.

\section{Discussion}

The response rate in our study was high with $82 \%$. This has been the case also in earlier Swedish and Norwegian studies on living kidney donors $[9,10]$. There is a recent French study published on long-term follow-up of 310 living donors and in this study 66\% responded [11]. Another published paper from Canada, Australia and Scotland, showed a response rate on $48 \%$ [12].

Voluntarism and altruism are prerequisites for living donation. It is encouraging to find that the strongest motive for donation in our study was the wish to help someone in need. This is also in agreement with an interview study performed prior to donation [13].

To donate a kidney is a major surgical event which means risks and a certain recovery time. Time for recovery was 1 - 2 months for half of the donors and sick-leave were 4 - 7 weeks for the majority of the donors. Thus, it is important that the donors are offered the time needed for recovery since $85 \%$ of them were working at the time of donation in this study.

Of the responders $12 \%$ indicated that they still had some health problem related to the donation, the largest problem being pain which was reported by $4 \%$. Though, we do not know if this pain is due to the donation procedure. However, it is a common problem with chronic pain in the general population, reported to be over $20 \%$ in the North American population [14,15]. A recent publication by Owen et al. on pain after nephrectomy show that $12 \%$ experienced chronic pain after donation and the donors did not receive adequate treatment [16]. It is noteworthy that pain after surgery is not classified as a major complication according to the Clavien system, where major complication includes an intervention, surgical or radiological [17].

Another finding in our study was that the majority of the donors were satisfied with the given information. Both written and verbal information are given to the donors but we think the information must be more individualised or elaborated to reach every potential donor. Guidelines support the necessity of adequate information
[18].

The most interesting part was the comparison between sibling and spouse donors. Today a spouse donor is as common as a sibling donor in Sweden. Who should be preferred? Our study indicates that the spouses donate a kidney to get a better quality of life as well as the quality of life for the family in total. The sibling donors express moral duty as a greater motive. In contrast to a recent published Norwegian study we could not find that the spouse donors had more doubts about the donation [10]. On the contrary, the spouse donors felt well-informed, they knew the expected results, became very satisfied and had an increased self-esteem.

Is psychosocial support necessary? We could find some donors who reported that they did not recover, and some with persisting economical problems. It is important to identify these problems early. On the other hand we do not know if it was the donation process per se or co-existing incidents in their life or pre-donation problems that we were not aware of at the time of donation. A thorough psychosocial investigation before donation is of great importance.

Are check-ups necessary? There was uncertain information about this issue. Some donors stated that they were promised check-ups they never received. About $75 \%$ had had some check-ups, which is better than a previous study from Sweden showing that 50\% were being controlled [9]. According to our medical study on blood pressure and kidney function made at the same time on these donors we found that two donors had undergone kidney transplantation and that one kidney donor was on dialysis. We also found that two donors had chronic kidney disease stage 4 and may be starting dialysis [8]. Also, the figure of hypertension was in agreement with our clinical finding with 25\% having treatment for hypertension. Our aim is that the donors should be offered medical check-ups on a regular basis, with a minimum of every 5th year after the first year post donation [8].

In summary, our study shows that the donor population is in good psychosocial health. It is a positive development that spouses can be living donors. They seem to be the winners.

\section{REFERENCES}

[1] J. M. Cecka, "Kidney Transplantation in the United States," Clinical Transplants, Terasaki Foundation Laboratory, Los Angeles, 2008, pp. 1-18.

[2] U. Heemann and L. Renders, "State of Living Kidney Donation in Europe," Nephrology Dialysis and Transplantation, Vol. 27, No. 6, 2012, pp. 2166-2170. doi:10.1093/ndt/gfs144

[3] L. Westlie, P. Fauchald, T. Talseth, A. Jacobsen and A. Flatmark, "Quality of Life in Norwegian Kidney Donors,” Nephrology Dialysis Transplantation, Vol. 8, No. 
10, 1993, pp. 1146-1150.

[4] E. M. Johnson, J. K. Anderso, C. Jacobs, et al., "LongTerm Follow-Up of Living Kidney Donors: Quality of Life after Donation,” Transplantation, Vol. 67, No. 5, 1999, pp. 717-721. doi:10.1097/00007890-199903150-00013

[5] D. Ummel, M. Achille and J. Mekkelholt, "Donors and Recipients of Living Kidney Donation: A Qualitative Metasummary of Their Experiences," Journal of Transplantation, Vol. 2011, No. 2011, pp. 1-11. doi:10.1155/2011/626501

[6] S. G. Jowsey and T. D. Schneekloth, "Psychosocial Factors in Living Organ Donation: Clinical and Ethical Challenges," Transplantation Reviews, Vol. 22, No. 3, 2008, pp. 192-195. doi:10.1016/j.trre.2008.04.008

[7] A. Lennerling, I. Blohmé, O. Ostraat, H. Lönroth, M. Olausson and G. Nyberg, "Laparoscopic or Open Surgery for Living Donor Nephrectomy," Nephrology Dialalysis Transplantation, Vol. 16, No. 2, 2001, pp. 383-386. doi:10.1093/ndt/16.2.383

[8] I. Fehrman-Ekholm, N. Kvarnström, J. Softeland, et al., "Post-Nephrectomy Development of Renal Function in Living Kidney Donors: A Cross-Sectional Retrospective Study," Nephrology Dialysis Transplantation, Vol. 26, No. 7, 2011, pp. 2377-2381. doi:10.1093/ndt/gfr161

[9] I. Fehrman-Ekholm, B. Brink, C. Ericsson, C. G. Elinder, F. Dunér and G. Lundgren, "Kidney Donors Don’t Regret. Follow-Up of 370 Donors in Stockholm since 1964," Transplantation, Vol. 69, No. 10, 2000, pp. 2067-2071. doi:10.1097/00007890-200005270-00016

[10] G. Mjoen, K. Stavern, L. Westlie, et al., "Quality of Life in Kidney Donors,” American Journal of Transplantation, Vol. 11, No. 6, 2011, pp. 1315-1319. doi:10.1111/j.1600-6143.2011.03517.x

[11] C. Fournier, N. Pallet, Z. Cherqaoui, et al., "Very Long-Term Follow-Up of Living Kidney Donors,” Trans- plant International, Vol. 25, No. 4, 2012, pp. 1-6. doi:10.1111/j.1432-2277.2012.01439.x

[12] K. Clemens, N. Boudville, M. A. Dew, et al., "The Long-Term Quality of Life of Living Kidney Donors: A Multicenter Cohort Study,” American Journal of Transplantation, Vol. 11, No. 3, 2011, pp. 463-469. doi:10.1111/j.1600-6143.2010.03424.X

[13] A. Lennerling, A. Forsberg, K. Meyer and G. Nyberg, "Motives for Becoming a Living Donor," Nephrology Dialysis and Transplantation, Vol. 19, No. 6, 2004, pp. 1600-1605. doi:10.1093/ndt/gfh138

[14] J. Hardt, C. Jacobsen, J. Goldberg, R. Nickel and D. Buchwald, "Prevalence of Chronic Pain in a Representative Sample in the United States," Pain Medicine, Vol. 9, No. 7, 2008, pp. 803-812. doi:10.1111/j.1526-4637.2008.00425.x

[15] D. Schopflocher, P. Taenzer and R. Jovey, "The Prevalence of Chronic Pain in Canada," Pain Research and Management, Vol. 16, No. 6, 2011, pp. 445-450.

[16] M. Owen, P. Lorgelly and M. Serpell, "Chronic Pain Following Donor Nephrectomy-A Study of the Incidence, Nature and Impact of Chronic Post-Nephrectomy Pain,” European Journal of Pain, Vol. 14, No. 7, 2010, pp. 732-734. doi:10.1016/j.ejpain.2009.11.013

[17] D. Dindo, N. Demartines and P. A. Clavien, "Classification of Surgical Complications: A New Proposal with Evaluation in a Cohort of 6336 Patients and Results of a Survey," Annals of Surgery, Vol. 240, No. 2, 2004, pp. 205-209.

[18] The European Parliament and the Council of the European Union, "Directive 2010/45/EU of the European Parliament and of the Council of 7 July 2010 on Standards of Quality and Safety of Human Organs Intended for Transplantation, 2010,” 2010. http://eur-lex.europa.eu/LexUriServ/LexUriServ.do?uri= OJ:L:2010:207:0014:0029:EN:PDF 